\title{
MODERN AN/ESTHESIA.
}

\author{
By RONALD JARMAN, D.S.C., M.R.C.S. (Eng.), D.A.
}

(Anasthetist to the Royal Cancer Hospital; Senior Ancesthetist to The Princess Beatrice Hospital, Gordon Hospital, and Woolwich War Memorial Hospital.)

Anæsthesia has changed considerably during the last ten years. It is often said, and rightly so, that this branch of medicine has advanced more than any other. Nevertheless the main factor, that is, the patient, remains the same since the days of Simpson. The patient's comfort is considered before everything else, and this point of view is always held before the eyes of the research worker. The patient has the right to expect the anæsthetic which is considered the safest and the best, and also the one likely to give him the least trouble before, during and after the operation. In this he is guided by his own private doctor, or by the surgeon in whom he has placed his trust. The anæsthetist is consulted and makes his decision on the general aspect of the patient, both clinical and psychological.

As far as possible, every patient who is about to undergo a major surgical operation should be carefully examined. This should include a blood and urine analysis in addition to a general clinical examination. Special attention should be paid to the blood pressure; and the cardiac energy index is regarded as a good indication of general condition. The majority of patients fall into one of the following three categories:-

(I) Those who demand to be put to sleep in their beds.

(2) Those who do not mind whether they are put to sleep in bed or on the operating table, but still wish to be unconscious of the operation.

(3) Those who desire to remain conscious whilst the operation is being? performed.

It is with this picture of the patient of to-day that the anæsthetist is faced and his work is not made easier by the publicity given to modern methods in the lay press, or the fact that every patient reacts differently to any anæsthetic that may be given him. Therefore ultra-modern methods cannot be said to suit every type of patient; and yet with the recent advances in pre-medication, it is very nearly possible to satisfy the demand of the most difficult.

\section{Premedication.}

This is probably as good a name as any other for this branch of anæsthetics. lt implies the administration of a mild drug so as to produce a form of sleep before operation. This renders the patient quiet and peaceful, with his mind at rest.

Opium. The first recognised drugs used for premedication were morphia and atropine given hypodermically. Then various compounds were made containing morphia, atropine and hyoscine. Later omnopon was produced, and this was followed by the combination of omnopon and scopolamine which produced the condition known as "Twilight Sleep." The dosage of morphia has been widely discussed in the past few years and it has been suggested that morphia alone is a drug that should be treated with great respect, but larger doses of its alkaloids may be given. There are three alkaloids of scopolamine, a dextro-rotary, a lævo-rotary, and a combination of the two, the dextro-rotary being exciting and the lævo-rotary depressant. It is advisable to give the lævo-rotary alkaloids of scopolamine with omnopon. 
The dose of morphia alone ranges from $\mathrm{gr}$. I/I2 to gr. I/3 for adults, according to the state of the patient. Omnopon can be given in doses of gr. I/3 and gr. 2/3. Omnopon gr. I/3 contains gr. I/6 of morphia; gr. $2 / 3$ contains gr. I/3 of morphia. Omnopon gr. I/3 with scopolamine gr. I/300 can be given to a young adult of the age of fifteen with reasonable safety, providing the patient is not too ill, when two-thirds of that dose would probably suffice. It is therefore easy to tabulate the doses of omnopon and scopolamine. The average dose administered to-day is :-

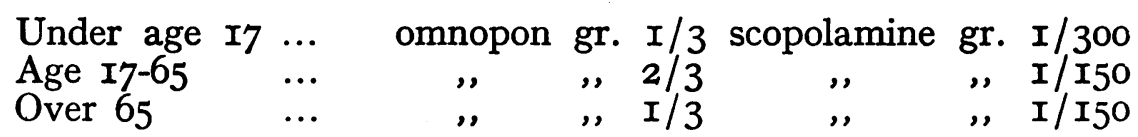

If the patient is extremely ill, the dose should be reduced to omnopon gr. I/3 and scopolamine gr. I/300.

If this is given one hour before the operation, the patient has a very pleasant period before any other drug is employed, and after the anæsthetic has been administered and he has returned to bed, there is a 'carry-over' effect for some hours, and therefore he is without pain or discomfort for some considerable time after the operation.

Barbiturates. The most popular and most discussed modern premedication group is that of the barbiturates, some of which can be administered by the mouth. Nembutal capsules are of considerable value, providing the patient does not suffer from hyperacidity and has not had a meal within the last hour or two. The following is the oral dosage:

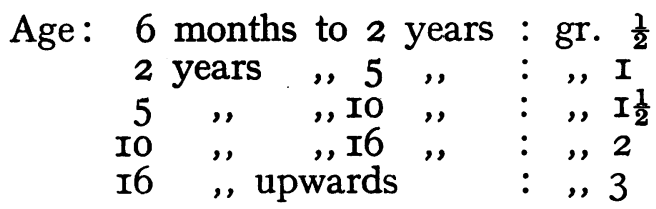

The capsule is administered 45 minutes before the operation and, if the patient shows no sign of being asleep half an hour later, a further gr. $\frac{1}{2}$ may be given. The other barbiturates administered per oram are medinal and dial, but they are seldom used; some anæsthetists occasionally give 5 or Io grains of medinal to adults (not children) twenty minutes to half an hour before operation.

Rectal Anæsthetics. Other premedication drugs are given per rectum. Paraldehyde is more popular for children, though some people give it to adults. The method was established by Rowbotham and the dosage depends upon the condition of the patient. It is worked out by stone weight for children and adults alike, I drachm of the solution being given per stone weight of the patient, and mixed with I oz. of distilled water at blood heat. Glucose used to be administered as well but this has been given up. There is a definite antipathy towards it owing to its smell, and yet the people who use it a great deal are loud in its praise. Of course there is always a danger of a mild colitis, but this is so rare that it can be more or less ignored.

Avertine was established in this country by Shipway and Bloomfield and has now a very large following. The dose of this drug also is decided by the weight of the patient and Bayer's table is an extremely good and sound guide. This prescribes per stone of body weight II minims of the avertine fluid mixed with one ounce of distilled water at blood heat and administered per rectum twenty minutes 
to half an hour before the operation. Avertine given in this way is usually extremely efficient, and adults can also receive atropine gr. I/ Ioo ten minutes or a quarter of an hour before going to the theatre. The mixture must always be checked by dropping two or three drops of Congo Red into it and seeing that it does not turn blue, i.e., that the avertine fluid has not decomposed during mixing. This means of inducing sleep before operation is extremely popular, though there is quite a definite, though small, percentage of restlessness after the operation. It is more marked in children than in adults, but if it happens with a highly-strung adult the sisters or nurses in charge may find him extremely difficult to control. The greatest danger with this drug is that of leaving the airway uncontrolled; no patient who has had avertine should ever be left without an airway in situ, to prevent the tongue falling back.

Numerous drugs are now being produced in the form of rectal suppositories. The one that, though still in its infancy, has been tried more than any other at the moment is nembutal. The average dose is I grain per year of age minus one; i.e., for a child of five years, 4 grains. Six grains is the highest dose for any child. The dose is :-

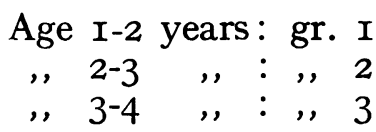

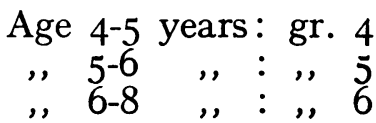

The nembutal suppository is given at least two hours and a half before the operation for all ages from 6 months to 8 years. For older children, e.g., from 3 to 8 years, it is sometimes advisable to give a one-grain suppository after the rectal tempera? ture has been taken at night, and the actual dose first thing in the morninge assuming that the operation is to be performed between the hours of 9 and ro a.m? Atropine can be given 20 minutes to half an hour before the operation and the child is then entirely unconscious of having had a needle put into its arm at all.

This drug is more suitable for children and is only used for adults to help in painful dressings. A six grain suppository given to an adult two or three hours before his dressing quietens him down and avoids an unpleasant experience caused by a painful dressing.

The other types of suppository are made chiefly by German chemical firms and act more or less in the same way as nembutal, and are given at longer or shorter intervals.

Intravenous Barbiturates. The most modern method of premedication is the intravenous method. This can be used before any operation, whether it be in the dental chair on young healthy adults or in the operating theatre. The patient can have it in his bed or on the table. Some prefer to give omnopon and scopolamine one hour before the operation and a small dose of evipan or pentothal whilst the patient is in bed before transporting him to the theatre. This is the ideal method. Others prefer to omit the omnopon and scopolamine; they give 3 or 4 c.c. of the drug intravenously while the patient is in bed, carry him straight away to the theatre, administer 2 or 3 c.c. more and then carry on with nitrous oxide and oxygen or small doses of the drug intravenously. It is important to note that these two drugs are here used for premedication or as a basal and not as a complete anæsthetic; therefore the minimal dose and not a maximal one should be given to the patient while in bed. I wish to stress that anæsthetists should give small doses and repeat, rather than maximal doses and hope for the best. 


\section{Choice of Anæsthetic.}

This is difficult inasmuch as there are five groups: (I) Inhalation; (2) Spinal; (3) Local; (4) Intravenous; (5) Combination of one or more of the other methods.

\section{Inhalation Anæsthesia.}

Nitrous Oxide. It is rapidly being realised everywhere that the anæsthetic of choice is nitrous oxide and oxygen administered by the McKesson apparatus. The following are the reasons for its popularity:-

(I) It is the safest and the least toxic of all general anæsthetics, and there is therefore little sensitisation of the tissues to surgical shock.

(2) Induction is pleasant for the patient, even if little or no premedication has been given, while large doses of narcotic may safely be given beforehand, so that after the operation the patient cannot remember that he has been moved from his bed.

(3) Surgical relaxation is quickly obtained.

(4) Operations with the diathermy knife can be done with absolute safety.

(5) Bodily functions are scarcely interfered with, and the clinical state is not aggravated.

(6) The most desperate cases may be operated upon with comparative safety so far as the anæsthetic is concerned.

(7) Dangerous signs of an overdose are conspicuous enough to give timely warning, and the respiratory centre remains responsive until late.

(8) In the absence of premedication, recovery of consciousness and rational control is almost immediate, even after prolonged administration.

(9) After-effects are conspicuously absent. There is never any vomiting, except when it is caused by other conditions, and so thirst may be quenched and nourishment taken soon after the operation.

(I0) The anæsthetic may with safety be repeated several times at short or long intervals.

(II) The stay in hospital is shortened and the convalescent period is reduced.

The advantages of the McKesson apparatus are:-

(I) It delivers the mixture at the percentage desired, whether the breathing is shallow or deep, whether rebreathing is employed or not, and whether the pressure of the gases is high or low. simply.

(2) The percentage of oxygen can be varied accurately, definitely, and

(3) Rebreathing can be employed at all pressures.

(4) The pressure at which the gases are delivered can easily be varied at will without disturbing the percentage of oxygen in the mixture.

The scope of nitrous-oxide-oxygen anæsthesia is unlimited. By means of the ordinary face-piece any operation may be performed, though spinal anæsthesia gives a better relaxation for abdominal work. In order to exteriorise the larynx a transnasal intratracheal tube can be passed and prevents anything from going down into the trachea or bronchus. A direct intratracheal tube may be passed for nasal operations, and the field of operation can be completely shut off and the patient entirely covered without any danger whatsoever. Dental operations and tonsillec- 
tomy can also be done with safety. Further, this form of anæsthesia is extremely valuable in all midwifery cases, whether it be a natural delivery, a forceps case or a Cæsarean section. It can be given intermittently during the first two stages and continuously for the third. The uterine contractions are actually strengthened, thus shortening the time of labour. The mother's condition is definitely better than when chloroform is used, and the baby is not affected in any way, and usually cries as soon as it is born.

Ether and Ethylene. Ether should never be used unless a patient is definitely resistant, or for a tonsil operation on a child. I suggest that ethyl chloride induction after some form of premedication and followed by gas and oxygen and ether is the ideal anæsthetic for a child having his tonsils and adenoids removed. Rarely, an anæsthetist may have to use ether in conjunction with nitrous oxide and oxygen because the surgeon demands it, or if the patient is very resistant. A slight trace of ether, supplemented by a little carbon dioxide, usually produces sufficient relaxation for the surgeon to complete any operation in the abdomen. No ether should have to be given for any operation outside the abdomen; there is no need for it if suitable premedication has been given.

The other forms of inhalation anæsthetic are ethylene and cyclopropane. Ethylene is only being used very sparingly in this country.

Cyclopropane is still being investigated and a great deal of work on this new gas has been done by Rowbotham and other anæsthetists at the Royal Cancer Hospital. In America this gas is still under control and will not be liberated for general use until the investigators are satisfied regarding its advantages and dis advantages and possible dangers.

\section{Spinal Anæsthesia.}

This form of anæsthesia has had more ups and downs than any other. At different times during its history it has been used extensively by anæsthetists all over the world and then, for some unknown reason-probably an accident which has rightly or wrongly been attributed to the anæsthetic-it has fallen into disrepute. In the last few years, thanks to the discovery of percaine, spinal anæsthesia has begun to come back into its own. In this country, the late Howard Jones was responsible for establishing it and for producing the method which now bears his name, as well as the solution he used; which is now copied throughout the four corners of the world.

The advantages of a spinal anæsthetic are:-

(I) It can be employed in certain cases where an inhalation anæsthetic must be avoided.

(2) It produces a complete anoci-association - that is cutting off all apparent pain impulses-and adequate relaxation in abdominal surgery.

(3) Spinal anæsthesia does not increase the sensitisation of the tissues to histamine so that shock is considerably less than with an inhalation anæsthetic such as ether or chloroform.

There are, however, certain disadvantages, namely: headache, pain in the back, severe nausea and vomiting, paralysis and sudden collapse. The most apparent one, which is apt to disturb the beginner, is the sudden fall in blood pressure during the operation. The cause of this is being investigated and has not yet been definitely ascertained. Some anæsthetists say that if a patient has a good pulse pressure the fall in blood pressure after administration is not so great, but if the pulse pressure is low, the fall might be considerable. 
The main methods of spinal anæsthesia are two, though possibly other users may have their own favourite technique. The methods that have impressed the majority of surgeons to-day are:-

(I) The Howard Jones technique ;

(2) The Etherington Wilson technique.

The Howard Jones technique has been described so many times that it is hardly necessary to repeat it here. Briefly, the patient is placed on his side, with his back arched, the spinal anæsthetic is administered, and the patient is then turned on to his face for seven minutes in the partial Trendelenburg. position, and then reversed again on to his back. Some note is taken of the length of the spinal cord. The dosage varies according to the operation, that is to say, for a high operation I5 c.c. for a man and I4 c.c. for a woman, i.e., I c.c. less of I:I500 percaine is given to the female than to the male. For low abdominal operations, ro or I2 c.c. are ample.

Etherington Wilson's technique, which I have used for some time in a large number of cases, is, in my opinion, the ideal method. The technique is much the same as recommended by Howard Jones except that the patient is sitting up, and a stop-watch is required. The spinal needles, syringes and bayonet needle are all boiled in distilled water and then put into warm distilled water. If they have previously been in spirit it is important to clean them carefully from all spirit before they are used. The I:I500 percaine ampoule is placed ready in very hot saline or water. The patient has had omnopon gr. 2/3 and scopolamine gr. I/I50 one hour before going to the theatre or anæsthetic room. The eyes are carefully but lightly bandaged, and all is quiet while the spinal anæsthetic is being given. The patient is asked to sit up and the back is prepared under complete sterile conditions, that is to say, the anæsthetist wears sterile gown, mask and gloves, the back is painted with spirit and with warm saline and sterile towels are placed on the table at the base of the back, on which the needles and syringes are laid. Not until the site of location has been found is the ampoule of percaine broken, so as to ensure that the saline is about blood heat before being injected into the theca. A wheal is made over the second or third lumbar space and the bayonet needles pierce the skin; the spinal needle is then introduced firmly but not roughly into the theca, the patient bending as far forward as possible and, as soon as the spinal fluid comes through steadily, and not intermittently, the syringe is fixed to the spinal needle and the required amount of percaine solution injected. For example, in an abdomino-perineal excision of the rectum 15 c.c. are administered to a male, and this takes about 20 seconds. The needle and syringe are withdrawn in one movement. Then the patient is asked to sit bolt upright and remains in that position for a maximum time of 45 seconds. The whole administration from start to finish takes no longer than 65 seconds.

In the technique described by Etherington Wilson I5 c.c. of percaine are given intrathecally and, after the patient has sat upright for 25 seconds, there is complete anæsthesia from the pubes downwards. In 35 seconds, there is anæsthesia from the umbilicus downwards; after 45 seconds, from the hypogastrium downwards. These times are fairly accurate. It must be remembered that the patient must not sit up for longer than 65 seconds. As soon as the time is up, the patient is put quietly on to his back, the table put into the Trendelenburg position, and the operation can proceed at once.

After a spinal anæsthetic it is kinder and wiser to get the patient to sleep while the operation is being performed, and therefore nitrous oxide and oxygen is 
administered. Often a little higher percentage of oxygen is required than without a spinal anæsthetic, but this is not invariably the case.

This method is obviously of extreme value for a patient who has a very large abdomen or large abdominal tumour, or who is exceptionally heavy. There is only one movement and the operation can proceed. Moreover, it has been definitely shown, in a large number of cases, that there are fewer headaches and less frequently spinal sequelæ after this method than after any other. Now that various other spinal administrators have seen the value of this technique, it is being used more extensively than it was a year or so ago.

Various attempts have been made to reduce the fall in blood pressure that follows a spinal anæsthetic. On the Continent ephedrin has been given at various stages ranging from 20 minutes to a few seconds before the spinal anæsthetic. Ephedrin has also been given immediately after the spinal anæsthetic and up to the time when the fall in blood pressure has become less marked. It is difficult to know whether this drug has any real value, and yet in a large number of cases it certainly helps the patient and brings the blood pressure back within normal limits. Recently, mixtures of ephedrin and cardiosol or ephedrin and coramine have been used, given five minutes and immediately before the spinal anæsthetic. The results up to now have been excellent. But, as has been remarked before, it is purely a question of the pulse pressure and the age of the patient. Where the anæsthetist is anxious about the condition of the patient, it is advisable to give one or two of these drugs so as to keep the blood pressure within normal limits. At the present time most authorities think that if they are given a few moments before the spinalo anæsthetic, the patient will not suffer from any form of spinal shock. Other users: have actually given ephedrin before the spinal anæsthetic and during the operation? with great success.

\section{Local Anæsthesia.}

Local anæsthetics have a limited following. Finnisterer, of Vienna, has popularised them to a certain extent, and Labat produced a technique for all types of operations. There are numerous solutions, the most popular being percaine, novocain and planocain. Each of these has its own users, but percaine has a definite advantage. It has a very prolonged effect and therefore relieves the patient of discomfort for some considerable time, and it has definitely been proved to be less toxic, and therefore admirable where large doses have to be given. The other drugs have been used in a large number of cases, and each anæsthetist and surgeon will continue to use the one he likes best.

\section{Intravenous Anæsthesia.}

It is natural that there should be some hesitation about injecting into the circulation a drug which cannot afterwards be withdrawn, and therefore objection is sometimes taken to the intravenous use of the barbiturates for anæsthesia. Against this, however, is the fact that they are used in extreme dilution and are katabolised extraordinarily rapidly, leaving no ill-effects behind. This makes them less obnoxious than ether, chloroform or any form of inhalation anæsthetic except nitrous oxide-oxygen. There is no sense of suffocation, practically no psychic shock, a remarkable freedom from vomiting and a complete absence of delayed poisoning.

The barbiturates used for intravenous anæsthesia fall into two groups: heavy and light. The heavy, including nembutal, pernocton, sodium amytal and Di-dial, are slowly broken down and are found in the excreta up to 72 hours after adminis- 
tration; accordingly it is preferable to use them as narcotics and not as general anæsthetics. The light barbiturates, evipan sodium, eunarcon, and pentothal sodium are broken down so fast that barely a trace can be found in the excretions after I2 hours. For all practical purposes their effect has passed off in from 3 to 30 minutes, according to whether a minimal or a normal dose has been used. Provided reasonable precautions are taken, they appear to be quite safe for all minor operations and as a means of induction, or even total anæsthesia, for a very large proportion of major operations.

For minor operations-e.g., dental extractions, the opening of boils and whitlows, the removal of nails and the setting of fractures-no preliminary medication is needed and only the minimal dose should be used. Usually 3 c.c. of evipan or pentothal are sufficient. For major operations on patients in an institution, premedication with omnopon and scopolamine is given.

The intravenous anæsthetic may be given in one of three ways:-

(a) As a single dose. This is used for an operation which is likely to last from Io-20 minutes-e.g., œesophagoscopy, bronchoscopy, cystoscopy and cystodiathermy, sigmoidoscopy and dilatation and curettage.

(b) Repeated doses. If the effect of the anæsthetic begins to pass off, a second dose may be administered by the intravenous route.

(c) By continuous intravenous infusion.

Any operation that is found to take longer than was anticipated may have its anæsthetic supplemented either by a further intravenous dose as described above, or by an inhalation anæsthetic.

The induction period is dramatic, smooth and pleasant. Most patients go to sleep without yawning. One of the most important points to note in using pentothal or evipan for surgical anæsthesia is that the respirations become shallow, but their rate and rhythm remain unchanged. If the anæsthetic is injected too quickly, the respirations may become imperceptible and it is therefore advisable to allow a safety pause during administration. When it is carefully injected, the respiratory depression is not great, and in the majority of cases is rapidly overcome by healthy young adults. In older people the return to normal is delayed.

The airway is of vital importance, and an appropriate dental prop must be inserted before the anæsthetic is given. If the respiration becomes too depressed, oxygen or carbon dioxide and oxygen may easily be administered through the Hewer's airway, which may with advantage be replaced by a Phillips's airway as soon as the patient is unconscious. Throughout the operation the angle of the jaw must, of course, be supported, with the head on one side or partially extended.

Often the patient becomes slightly cyanotic, especially the older patient. A well-maintained airway, with or without a little oxygen, soon restores the colour. The pulse quickens as soon as the first two or three c.c. have been given. It gradually loses some of its volume, but returns to normal within a few minutes. If strict attention be paid to the patient's colour, the pulse does not become weak. The pupil first dilates, but soon becomes normal. The corneal and the conjunctival reflexes are lost for the whole time that the drug is acting as a surgical anæsthetic. As soon as it starts to wear off, the reflexes return to normal. No 
tremors have been seen except where the minor operation has been started before complete surgical anæsthesia had developed; in this case tremors started and took two or three minutes to disappear.

Most patients recover a little more quickly with pentothal than with evipan, and their minds are clearer. There is no post-operative restlessness and no cause for anxiety, provided the airway is properly maintained. Varying degrees of post-anæsthetic drunkenness occur, but this passes off more quickly than after evipan.

If a small or greater part of the solution is injected into the subcutaneous tissues, there will be a definite local reaction with pentothal but not with evipan. It is of course important that the syringe and needles be free from all spirit. If the drug is given too quickly there is a dangerous depression of the respiratory centre.

Advantages and Disadvantages. The main differences between evipan and pentothal are:-

(I) Induction with pentothal is a little smoother.

(2) Pentothal seldom produces the twitching or jactitation which is occasionally seen with evipan.

(3) The fall in blood pressure is less noticeable with pentothal than with evipan.

(4) The main disadvantage of pentothal is that it is more depressant to the respiratory centre, and for this reason it is advantageous to have a McKesson apparatus at hand to administer oxygen and $\mathrm{CO}_{2}$ under pressure if required.

(5) A few patients complain of a sulphurous taste or smell for a short time after pentothal.

Contra-Indications. These light barbiturates are metabolised in the liver very rapidly, and any gross hepatic disease or the presence of jaundice is a definite contra-indication. General feebleness of the patient and low blood pressure make it inadvisable to use doses that are apt to cause fall in blood pressure.

Owing to the fall in blood pressure with all intravenous barbiturates, the recumbent posture is the safest for the administration of these anæsthetics. Several untoward incidents have been encountered in the dental chair, even with healthy patients. Lack of available space applies only to institutions where a large number of patients are to be dealt with and where enough room is not available to allow them all to recover sufficiently to return home.

As a general rule it is not advisable to give any barbiturates intravenously after other barbiturates have been given as premedication.

Antidotes. The antidotes to pentothal or evipan do not differ from those of any other form of general anæsthetic, nor are they more frequently required. Coramine is by far the most reliable drug for collapse and it should be used liberally. Five cubic centimetres is the average dose, and Io c.c may be given for severe collapse. It may be given subcutaneously or intramuscularly or, in emergency, intravenously. It has a stimulating effect on the heart and respiration. Alpha-lobeline is a direct respiratory stimulant and is used in doses of gr. 3/20 or 3/Io either subcutaneously or, in urgent cases, intravenously. Another direct 
stimulant is $\mathrm{CO}_{2}$. It is given preferably under pressure in the proportion of 5 or $7 \frac{1}{2}$ per cent. $\mathrm{CO}_{2}$ to oxygen. A cylinder of this mixture should be in every operating theatre and in every recovery-room.

Technique. (I) Single dose. The sterilised syringe having been charged, a dental prop or Hewer's mouthpiece is inserted between the patient's teeth. The upper part of the arm is constricted, either manually or by a pressure armlet, and the needle inserted into an antecubital vein. If the dose is to be Io c.c, the first 2 or 3 c.c. of the solution are injected in about $I_{5}$ seconds, during which time the patient is asked to count. He usually becomes unconscious in I5-30 seconds, and a pause is then advisable for about the same period, so that the anæsthetist may be satisfied that his condition is satisfactory. If the injection is given too rapidly, the pulse rate rises and the respirations become depressed. The next 3 or 4 c.c should be injected in about 30 seconds. After a further short pause, provided the patient's condition is still satisfactory, the remainder of the Io c.c. dose is given at the previous rate. Both the pulse and respiratory rates are constantly noted, a clear airway is maintained, and the jaw is supported throughout the anæsthesia.

(2) Repeated dose. If a further dose is likely to be wanted, the needle may be left in the vein and the syringe removed, recharged, and replaced if required. For this purpose Dixon Wright's splint, which controls the forearm, will be found convenient. This has an upper band, consisting of a pneumatic bag which can be inflated and deflated by means of a bulb with a release valve attached, and a lower band firmly gripping the wrist. The needle and syringe are fixed to the forearm and kept in place by means of adhesive plaster. for this:-

(3) Continuous intravenous infusion. Two forms of apparatus are available

(a) An ordinary intravenous apparatus is used to convey normal saline with 5 per cent. glucose from a flask container to a vein. The lotion need not be heated. A dripper, controlled by a simple thumbscrew, is adjusted to deliver not less than 20 and not more than 30 drops a minute. The limb is with advantage controlled on a suitable splint. The needle, attached to the syringe containing the intravenous anæsthetic, is inserted into the tubing near the vein and the injection given as into the vein.

(b) The Jarman three-way syringe. A Io c.c syringe with a three-way nozzle is fixed to the forearm with elastic bracelets. With the control in the central position, the barrel of the syringe communicates directly via the needle to the vein. When the control is turned to the left, the lateral feed communicates directly with the needle, and this position is used for continuous saline-glucose infusion as in the preceding method. When the control is turned to the right, the other lateral feed communicates with the barrel, and the syringe can thus be charged with a further dose of anæsthetic, which may then be injected through the needle by turning the control to the mid-position.

In serious cases a patient can, of course, have blood transfusion throughout the operation with pauses for the anæsthetic administration. Similarly, for any emergency, the syringe can be used for giving stimulants, such as coramine or alpha-lobeline; and here the advantage of the apparatus is that only the smallest amount of the drug need be given, since it is accurately measured and reaches the 
vein direct. The administration of continuous saline-glucose infusion during operation has been found of the utmost importance in some of the 'poor risk' cases. Dehydration is combated all the time and shock is largely abolished.

\section{Combination Methods.}

The final method is a combination of all the methods just described. In fact it has been rightly said that the best anæsthetic is one that is well balanced: in other words, a combination of one or more drugs, so as to produce a safe and reliable anæsthesia. It is easy to see that, with the different forms of premedication, nitrous oxide-oxygen combined with local anæsthesia would be the ideal method for various types of operations such as an appendicectomy, or gastrojejunostomy. There is no need to administer a local anæsthetic for any operation outside the abdomen when nitrous oxide and oxygen is combined with suitable premedication. Then again, nitrous oxide and oxygen and small doses of an intravenous anæsthetic combined with a local anæsthetic may be useful, as it may be desirable to reduce the dose of the intravenous drug. Another useful combination is nitrous oxide and oxygen with the minimum dose of an intravenous drug used as a basal; or the spinal anæsthetic combined with a basal, and followed by nitrous oxide and oxygen with a higher percentage of oxygen than usual. The number of types of anæsthetics which could be administered by using these four different methods is considerable. The methods which I have mentioned are at the present time popular and standard. 